\section{INTERNATIONAL GENETICS CONFERENCE}

$\mathrm{A}^{\mathrm{N}}$ $\mathrm{N}$ international genetics meeting took place during October 31-November 2 in London, the first to be held there since the conference in 1906 when Bateson first named the subject 'genetics'. Dr. C. D. Darlington, president of the Genetical Society, in welcoming the foreign visitors, said that after the First World War it had taken nine years to arrange an international gathering. On this occasion it had been possible in nine weeks. For this they were indebted to the help of the British Council, the French Scientific Mission, and the happy coincidence of Prof. Muller's Pilgrim Trust Lecture to the Royal Society.

Dr. Darlington summarized the development of plant genetics in Britain since 1939 under four heads. The first was the important beginning that had been made by Pontecorvo in the study of the genetics of fungi, especially on mutation, and the action of special mating systems described under the term 'heterokaryosis'. 'This work, of course, was closely related to the pioneer study of Prof. Winge on the breeding of yeast, and the later work of Lindegren, Beadle and others on yeast and Neurospora (see p. 52 of this issue). There had been theoretical interest also in the American studies of cytoplasmic inheritance in these organisms, especially in its bearing on the origin of cancer and of yirus diseases.

Second were the experiments of Mather on quantitative inheritance in plants and animals. Beginning with the analysis of selection, Mather had been able to develop Fisher's combination of geneties and statistics into a method of describing and predicting quantitative inheritance. His results, and the theory of polygenic behaviour based on them, were of the first importance for practical plant and animal breeding. But they seemed to be no less important for the theory of gene action and for the understanding of the physiological difference between heterochromatin and ouchromatin.

Third was the study of induced mutation. Two kinds of work had been carried out. One was that of Catcheside and Lea, who had used different types of radiation, including neutrons, to discover the physical method of gene alteration and chromosome breakage. The other was that of Darlington and La Cour, who had been concerned in discovering what happened after the breakage of chromosomes as a means of more accurately recording when and where chromosomes were in fact broken. These observations seem to show that the attachment of nucleic acid to the chromosomes, an attachment organized by the centromere, governed both their breakage and their later reunion. The work of Auerbach and Koller on chemically induced mutation and chromosome breakage (using mustard gas) seemed to fall into line with this conclusion.

Fourth were direct studies of nucleic acid relations with the chromosomes. Originally these relations were known to be controlled by temperature. Koller had now shown that they were physiologically controlled in mammals, and La Cour had shown that differentiation in the quantity of nucleic acid supply in the cell was the basis of the differentiation of red and white precursors in the blood.

These developments, Dr. Darlington concluded, showed that, in place of the simple relationship of chromosomes and heredity, we now had a triple relationship between the studies of heredity, ehromosomes and chemistry. There had been a new synthesis and this synthesis had been equally effective in developing the theory of the subject and in applying it usefully to the problems of agriculture and medicine.

Prof. J. B. S. Haldane, reviewing the advance in animal genetics, treated the groups in systematic order from Crustacea to man. He referred to Waddington's co-ordination of genetic abnormalities with the crises of development in flies, and to Ford's experiment in which selection changed the dominance of a naturally occurring mutant gene of the moth Abraxas. He described Fisher's theoretical and experimental studies with inbreeding in mice. Philip had found stocks of Drosophila subobscura growing in Nature which were heterozygous for inversions of pieces of chromosome and maintained this heterozygous condition on inbreeding for several generations. They were, therefore, like some species of CEnothera, true-breeding hybrids of a kind not previously known in animals. He pointed out that Kalmus had confirmed the French discovery of the cytoplasmic inheritance of sensitivity to carbon dioxide in Drosophila. In man, new data on crossingover between hæmophilia and colour blindness gave them 10 per cent recombination. In man also the new work on the $R h$ gene, which causes death of newborn babies, had shown that, of the eight allelomorphs and six anti-sera which Fisher predicted, seven allelomorphs and five anti-sera had now been described either by Race or by workers in the United States.

During the War also the work of Gordon and Sang showed that Drosophila melanoyaster homozygous for the gene 'antennaless', nevertheless grew antennæ if provided with a sufficient supply of vitamin $\mathbf{B}_{2}$. In other words, the mutant gene fails to carry out a specific chemical process, a situation analogous with that described by Beadle in Neurospora.

Dr. Julian Huxley discussed the development of genetics in Great Britain in relation to systematics and ecology. Ford had shown that the chemistry of the pigments in butterfiles' wings varied with their systematic grouping and in some cases enabled previous classifications to be rectified. Crosby had found a population of primroses in which a gene for homostyly appeared to be becoming fixed, replacing in part, at least, the normal heterostyle condition. Finally Lawrence's work on the differentiation of the species of Streptocarpus in south and south-east Africa seemed to be of outstanding importance for the theory of systematics. Dr. Huxley also referred to the case of the hooded and carrion crows, between which there was an interbreeding boundary two thousand miles long but only a few miles wide. This boundary was shifting southwards but remained narrow on account, it seemed, of the upset of polygenic balance which acted against the propagation of the hybrids.

A session on plant breeding was opened by Prof. $\varnothing$. Winge (Copenhagen), who described work he had carried out since discovering the processes of sexual reproduction in yeast. These processes made hybridization and systematic breeding possible. Apart from the ordinary segregation and re-combination resulting, he found a series of mutants, some of which were already in use for the production of new brewers' and bakers' yeasts. The mutant sectors of monosporous and single-cell cultures showed the characteristic expanding and contracting shapes owing to 
their changes in growth-rates relative to the original types.

Prof. M. J. Sirks (Groningen), who was working under extreme difficulty in Holland during the War, gave an account of the work he now has in hand. This related to species hybrids in Verbascum and Phaseolus, genetics and chemistry of flower colour in Vicia, where the pigments are not anthocyanins, and the breeding behaviour in an aberrant wild toadflax (Linaria).

Prof. A. Müntzing (Lund) reported his studies on tetraploid rye which gave very favourable crop yields provided it was separated from diploid rye : the cross between diploid and tetraploid occurred very readily and it was successful in producing an embryo but unsuccessful in producing a grain. He also discussed the types of rye with supernumerary chromosomes which exist in stocks of these plants throughout the world. He showed how the chromosomes were distributed to the generative nucleus of the pollen in disproportionate frequency and suggested that this gave them an unfair advantage in competition. This advantage was offset by their physiological disadvantage in reducing vigour and fertility. He therefore looked upon these chromosomes as piratical intruders in the genetic system of this plant.

Prof. Müntzing also described the astonishing discovery of a plant species, a diploid grass Poa alpina, which lost its supernumerary chromosomes in the roots. Such chromosome-diminution has long been known in the thread worm Ascaris, and has recently been found in another grass, a diploid Sorghum. The wheat-rye hybrid (Triticale) had given good results for baking quality, but so far indifferent yields. Gustafsson was making progress in barley breeding with the help of X-ray induced changes.

Dr. S. C. Harland (Lima) pointed out that in the castor oil plant the glaucous gene was rare on the coast of Peru, rapidly increased inland, and was present up to a height of $8,000 \mathrm{ft}$. The special equilibrium on the coast was correlated with the unusual climate of this narrow strip, which presented many problems of genetic interest. Native Peruvian peas which had existed as isolated races in the mountains since the Spanish conquest were extremely heterogeneous, and had been found to contain a recessive gene conferring immunity to mildew on them. This could be transferred to imported varieties.

The European potato differed genetically from Peruvian potatoes in regard to its photoperiodism. When brought back to Peru it grew no more than two inches high and produced tubers the size of peas. The European-Peruvian hybrids segregated sharply for this genetic difference. This evidence favours Chile as the main source of origin of European cultivated potatoes.

In a Drosophila session, Prof. O. L. Mohr (Oslo) described how he had been able to distinguish between the effects of deficiencies and lethal mutations in Drosophila by studying the comparative effects of different doses in triploids and in translocation hybrids.

Prof. B. Ephrussi (Paris) used deficiencies for another purpose. He sketched the evidence which distinguishes the physiological interpretation of the position effect in Drosophila, and his own interpretation. This assumes that the position of the chromosomes in the resting nucleus, being determined by somatic pairing, is abnormal in a structural hybrid. The chromosomes are, therefore, distorted mechanically as a result of their breakage, and their physio- logical action is correspondingly upset. The position effect has also been shown by Catcheside in CEnothera where somatic pairing does not occur. Dr. K. Mather suggested that the mechanical theory might apply with duplications within the chromosome, but Dr. D. G. Catcheside doubted whether his data agreed with this view. Prof. H. J. Muller described the work of Prokofieva on the conversion of the euchromatic to the heterochromatic state by the proximity of large masses of heterochromatin. These observations offered one possible explanation of the position effect.

Prof. P. L'Héritier (Strasbourg) explained the inheritance of sensitivity to carbon dioxide in Droso. phila. He showed that this sensitivity was predominantly, though not exclusively, maternal in its inheritance. Since it showed no regular segregation it must be considered to be cytoplasmic in its determination. It could be cured, however, sometimes temporarily, sometimes permanently, by heat treatment in early life. Dr. H. Kalmus explained that he produced the same cure by cold treatment. Prof. L'Héritier attributed these effects to an upset in the rate of development of cells relative to the rate of multiplication of plasmagenes produced by differences of temperature.

Prof. G. Teissier (Paris) described his experiments in maintaining mutant and wild-type populations of Drosophila in mixed culture. He was able to measure the competitive power of the different genotypes, some of which disappeared while others reached equilibrium. Cyclical changes in gene frequencies also occurred under conditions in which the survival rate was usually about one in ten. The experiments provided an experimental explanation of polymorphism and also of the rapid spread of new mutants in Nature.

Prof. J. Brachet (Brussels) outlined the work he had done on the concentration of ribose nucleic acid in the eggs of sea urchins and chicks in relation to the action of organizers in development, to evocation, and to the concentration of the dexosyribose nucleic acid used in the manufacture of chromosomes. $\mathrm{H}_{\theta}$ showed that the two forms of nucleic acid were fairly readily convertible. This work has depended on the use of ribonuclease and other enzymes as means of discrimination. The results agree with those reached simultaneously by Caspersson in Sweden, in showing that ribose nucleic acid is present in the nucleolus and in the cytoplasm, particularly in the ergastoplasm. There is a constant relationship between high ribose nucleic acid content and active protein synthesis in the cell. Ribonucleoproteins are present in the cell as small granules containing also important respiratory and hydrolytic enzymes. These granules may well play an important part in protein synthesis, and thus have some relationship with plasmagenes.

In a session on animal breeding Prof. A. L. Hagedoorn (Soesterberg) discussed the selective modification of dominance in poultry and mice. The autosexing property in poultry depends on the action of the barring gene in birds which have no black pigmentation. Barring is dominant in black birds, intermediate in Brown Leghorns, and nearly recessive in Rhode Island Reds. He had produced new types in various animals by hybridization and recombination as opposed to mutation, for example, the waltzing ferret, from a cross of ferret by fitch (polecat). Prof. Hagedoorn also described the strange case of the whisker-eating gene in mice which reveals itself only by the absence of whiskers in the individual's cage mates. 
Prof. G. Bonnier (Stockholm and Wiad) showed how he used the collection of identical twins he had made in cattle. Some thirty pairs of twins had been subjected to differential feeding treatments and the effects recorded in regard to both growth and milkyield. So far it had been shown that improved nutrition had a greater effect with some genotypes than with others. His results also showed that higher milk production was accompanied by slower growth, so indicating that the total physiological activity of the cow was limited, one increase only being made st the expense of another. With regard to these treatments, Dr. J. Hammond pointed out that age in cattle could often be more usefully measured in terms of development rather than time. Clearly Prof. Bonnier's experiments were of theoretical as well as practical value.

Several speakers referred to their work on human heredity. Prof. Mohr had studied the occurrence in Norway of a form of mental deficiency with a biochemical basis; that of failure to oxidize phenyl pyruvic acid in the kidneys. The whole medical profession of Norway had been circularized with the view of obtaining complete information on the occurrence of this hereditary defect. The results showed that it was concentrated especially in certain inbred island populations. The view that the gene determining this form of imbecility was an autosomal recessive, as advanced by Penrose, was confirmed. Prof. L. S. Penrose pointed out that the incidence of this defect was highest among the Nordic Europeans, although it occurred also among Africans.

Dr. Harland gave some results of his studies on human heredity in Peru. He said that the continuous eyebrow character, common in Spain, and favoured by Persian portrait painters, is fairly frequent in the Indian population of Peru, and seems to $b e$ inherited as a conditional dominant. Another character found only in isolated mountain populations was that of mottled finger-nails, the inheritance of which he had not yet dotermined. Both Prof. Mohr and Dr. Harland emphasized the value of isolated and inbred populations in the study of abnormal types and conditions in man.

\section{Discussion}

In addition to papers on work in genetics, there was a discussion on the future of genetics. Dr. Darlington said that thirty years ago Mendel had seemed the exclusive progenitor of genetics ; recently Darwin had been admitted as of equal importance, and very soon we might feel required to add Pasteur's name to the genealogy of the subject. The rapid expansion of genetics required some thought for the future. This expansion was taking place in different countries in different ways. Now was therefore a specially favourable moment for discussing the new applications of genetics to teaching and research and its new combinations, with physics and chemistry and with agriculture, medicine and sociology.

Dr. Huxley opened the discussion with an account of developments during recent years. $\mathrm{He}$ pointed out that the close union of genetic experiments with the study of physiology, embryology and systematics, of ecology and biochemistry, required a new outlook in both teaching and research. A new unity, in which evolutionary theory again played a prominent part, had been established and this could be of the utmost service to scientific thought.

Dr. U. Philip and Dr. M. J. D. White maintained that there was still great value to be attached to the formal and independent pursuit of specialized branches of the subject. They pointed out that the internal co-ordination of genetics and cytology alone gave great scope for future research. Dr. C. H. Waddington emphasized the dominant position of geneties in the organization of the modern study of life, a position which had only been acquired in the last ten years. He pointed out that wherever you started from you arrived at genetics. Whether you began with form or with function, genetic methods were necessary for the ultimate solution of your problems.

The foreign guests described the different methods by which genetics had developed in their different countries.

Prof. Winge pointed out that in Denmark genetics owed its origin to Johannsen, who was already teaching the subject in 1903, although a chair was only created in Copenhagen in 1921. The develop. menit of genetics in Sweden, Prof. Müntzing showed, arose from the practice of plant breeding, which was indeed also the foundation of agricultural research in Sweden. The importance of genetics for this work was discovered by Nilsson-Ehle, who was already carrying out genetic experiments after a visit of Tschermak in 1901. In consequence, genetics began at Svalöf. It was permanently established, however, in the neighbouring University of Lund when NilssonEhle became professor of genetics there. In addition to Svalöf, there were many other plant-breeding stations in Scania distributed around Lund. There was the Weibullsholm seed-breeding station, the Hilleshög sugar-beet station, a new forest-tree breeding station at Ekebo, and a fruit and vegetable breeding station at Alnarp. Moreover, there were the Svalöf filial stations distributed over the whole of Sweden and the important new station at Ultuna directed by Prof. Turesson. Animal breeding was concentrated in the hands of Prof. Bonnier at Wiad and at the Stockholm University College.

Prof. Ephrussi described an entirely different situation in France. Here there had, in the past, been no organization for teaching or research in genetics. In the new plans for the development of research in France, genetics was to play a significant part. A chair of genetics had been newly created at the Sorbonne to which he had been appointed, and the organization at the Château Gif would allow of the development of animal and plant breeding together with pure research in genetics, cytology and biochemistry.

Prof. Mohr pointed out that with the limited organization available in Norway, special departments of genetics did not yet exist. He gave courses to medical students which were entirely voluntary but well attended, and appreciated by the students as providing the only training in scientific method which was available in the medical curriculum. Prof. Mohr deplored the death of his countryman, Christian Wriedt, one of the greatest of animal breeders, whose success depended on his genius for securing the help and understanding of the farmers themselves.

Prof. Sirks said that in all four universities of Holland there were chairs of genetics, while he had been in charge of the department of genetics at the Agricultural College of Wageningen before he went to the University of Groningen. The system allowed of the co-ordinated teaching of genetics to biological, medical and agricultural students.

The International Genetics Committee met during the Conference and decided to invite the co-operation 
of Russian representatives as the first step to the organization of the Eighth International Congress, to take place, if possible, in 1947.

\section{Conclusion}

The Conference showed that, in spite of the War, decisive developments had occurred independently in the different countries represented. These developments were comprehensively summarized by Prof. Muller in his lecture, where he showed the primary importance of the concept of the gene in biology and more particularly in the application of physical and chemical methods to biology. It has, however, been on account of the War that a fuller use is now going to be made of this new genetics both in teaching and research in many different countries. A new epoch seems to be beginning in which biology will be treated as a whole.

\section{DOCUMENTARY REPRODUCTION}

\section{BY LUCIA MOHOLY}

$I^{T}$ $\mathbf{T}$ is becoming increasingly evident that docu1 mentary reproduction, the most popular group under the main heading mechanical aids to learning, is an invaluable help to men of science, educationists and other students. Among the various techniques available, preference has recently been given to microfilm as the quickest and cheapest method in all cases where one copy or a small number of copies are required. Another application of the micro-copying technique, the micro-card, is in preparation. It will be an addition, not an alternative, and does not affect the issues discussed here, since for the purpose of this article the relative merits of individual techniques are of secondary importance. However, we may expect to hear more of the micro-card in the near future.

It may be of interest to note that microfilm, after being invented more than seventy years ago, was completely forgotten, only to come into its own again when the need became imperative. In some countries, in particular the United States and Germany, microfilm was popular long before it became generally known in Great Britain. (One example may illustrate the extent to which it was used: before the War, 34 million cards in the U.S. Census Bureau, filed in 1,200 steel cabinets, occupying 7,000 sq. ft. of floor space, were microfilmed and thus reduced to occupy no more than 58 sq. ft.) Economy in storage space, bulk and weight, effected through microfilm, is now no longer unknown in Britain; nor are other purposes such as insurance against dangers of fire, water and enemy action. Precautions of this kind were taken everywhere and with great advantage during the War. Airgraph letters were one of the most outstanding examples of reduction in bulk and weight in air transport.

These obvious advantages, coupled with a few others of a less conspicuous kind, brought microfilm to the fore as a useful tool for purposes directly or indirectly connected with the war effort. Millions of documents were microfilmed in Britain and dispatched to distant places by air, and many millions of pages of varied literature, old and new, British and foreign, have been made available through the medium of microfilm to men of science and others all over the world. Large schemes have been sponsored by the
American Council of Learned Societies (manuscripts and early books in British repositories, for the United States), the Association of Special Libraries and Information Bureaux (foreign periodicals for Great Britain and the United States) and the British Council (British periodicals for China). Government departments, research institutions and scholarly bodies equally recognized the importance of the technique; and though some of the schemes are now coming to an end, the practical experience gained during the war years will be invaluable for the future. It must be assumed that emergency conditions will prevail for some considerable time and microfilm may be called upon to fill needs which cannot be satisfied by other means. But while hitherto most of the work was carried out by bilateral arrangement between the parties concerned, the type and extent of work awaiting attention in the future will require co-ordinated action and well-planned organ. ization.

Going through the Directory of Microfilm Sources, published by the American Library Association in 1941 (apart from a few exceptions still reasonably up to date so far as English-speaking countries are concerned-a new edition is in preparation), we find that most of the existing units which supply microfilm or other photographic reproductions for purposes of study and research were attached to, or sponsored by, scientific and other institutions, libraries, bibliographical centres, colleges, laboratories, research stations, archives, record offices, etc.

Generally speaking, the activities of the existing units cover a small range of the potential tasks now open to modern reproduction techniques. Their ser. vices have mostly been limited to the supply of microfilm or paper copies of periodicals otherwise unobtainable, or of extracts from books and period. icals needed in connexion with special lines of research. Some of the institutions give their services to members only, others to non-members also. The majority supply extracts from books and periodicals in their own libraries; a few only have established exchange and co-operation with other libraries and institutions, locate references, compile bibliographies, or issue abstracting journals to facilitate selection of subject-matter of which copies may be required. Examples of the latter group are: ASLIB Microfilm Service (London); Royal Society of Medicine (London); Institut de Documentation (Paris); Army Medical Library (Washington).

Many of us look upon documentary reproduction as a modern substitute for hand transcription. This is correct-up to a point; and it was generally correct-until quite recently. With the advent of the micro-copying technique, the potentialities of documentary reproduction have increased to an extent which was entirely unexpected until a few years ago, and they are now in the course of material. izing into new instruments ready to perform a great number of new tasks.

\section{Preliminary Programme of Tasks}

1. Issue of limited editions which may not justify the cost of type-setting; for example, dissertations, theses, private editions. The cost of a microfilm negative is comparatively low and can easily be covered by a slight increase on the cost of each positive. From an existing master negative, copies can be supplied individually upon request. There is no need for a minimum number of copies to justify investment, since the investment is negligible. 